\title{
High-sensitivity MALDI-TOF MS quantification of anthrax lethal toxin for diagnostics and evaluation of medical countermeasures
}

\author{
Anne E. Boyer • Maribel Gallegos-Candela • Conrad P. Quinn • \\ Adrian R. Woolfitt • Judith O. Brumlow • Katherine Isbell • \\ Alex R. Hoffmaster • Renato C. Lins • John R. Barr
}

Received: 5 December 2014 /Revised: 13 January 2015 / Accepted: 21 January 2015 /Published online: 12 February 2015

(C) The Author(s) 2015. This article is published with open access at Springerlink.com

\begin{abstract}
Inhalation anthrax has a rapid progression and high fatality rate. Pathology and death from inhalation of Bacillus anthracis spores are attributed to the actions of secreted protein toxins. Protective antigen (PA) binds and imports the catalytic component lethal factor (LF), a zinc endoprotease, and edema factor (EF), an adenylyl cyclase, into susceptible cells. PA-LF is termed lethal toxin (LTx) and PA-EF, edema toxin. As the universal transporter for both toxins, PA is an important target for vaccination and immunotherapeutic intervention. However, its quantification has been limited to methods of relatively low analytic sensitivity. Quantification of LTx may be more clinically relevant than LF or PA alone because LTx is the toxic form that acts on cells. A method was developed for LTX-specific quantification in plasma using anti-PA IgG magnetic immunoprecipitation of PA and quantification of LF activity that co-purified with PA. The method was fast $(<4 \mathrm{~h}$ total time to detection), sensitive at $0.033 \mathrm{ng} / \mathrm{mL}$ LTx in plasma for the fast analysis $(0.0075 \mathrm{ng} / \mathrm{mL}$ LTx in plasma for an $18 \mathrm{~h}$ reaction), precise (6.3-9.9\% coefficient of variation), and accurate $(0.1-12.7 \%$ error; $n \geq 25)$. Diagnostic sensitivity was $100 \%$ ( $n=27 \mathrm{animal} / \mathrm{clinical}$ cases $)$. Diagnostic specificity was $100 \%(n=141)$. LTx was detected post-antibiotic treatment in $6 / 6$ treated rhesus macaques and $3 / 3$ clinical cases of inhalation anthrax and as long as 8 days post-treatment. Over the course of infection in two rhesus macaques, LTx was first detected at 0.101 and $0.237 \mathrm{ng} / \mathrm{mL}$ at $36 \mathrm{~h}$ post-
\end{abstract}

\footnotetext{
A. E. Boyer · M. Gallegos-Candela · C. P. Quinn · A. R. Woolfitt •

K. Isbell $\cdot$ A. R. Hoffmaster $\cdot$ J. R. Barr $(\triangle)$

Centers for Disease Control and Prevention, Atlanta, GA 30341,

USA

e-mail: jbarr@cdc.gov

J. O. Brumlow $\cdot$ R. C. Lins

Battelle-Technical On-Site Professional Services,

Atlanta, GA 30329, USA
}

exposure and increased to 1147 and $12,107 \mathrm{ng} / \mathrm{mL}$ in latestage anthrax. This demonstrated the importance of LTx as a diagnostic and therapeutic target. This method provides a sensitive, accurate tool for anthrax toxin detection and evaluation of PA-directed therapeutics.

Keywords Anthrax - MALDI-TOF MS · Quantification · Lethal toxin - Lethal factor · Protective antigen · Diagnostic · Bacillus anthracis

$\begin{array}{ll}\text { Abbreviations } & \\ \text { 5PL } & \text { Five-parameter logistic } \\ \text { AIGIV } & \text { Anthrax immune globulin intravenous } \\ \text { ID } & \text { Isotope dilution } \\ \text { ISTD } & \text { Internal standard } \\ \text { LF } & \text { Lethal factor } \\ \text { LOD } & \text { Limit of detection } \\ \text { LTx } & \text { Lethal toxin } \\ \text { MALDI-TOF } & \text { Matrix-assisted laser desorption ionization } \\ \text { MS } & \text { time-of-flight mass spectrometry } \\ \text { MB } & \text { Magnetic beads } \\ \text { NNA } & \text { Normal North American } \\ \text { PA } & \text { Protective antigen } \\ \text { PCR } & \text { Polymerase chain reaction } \\ \text { SD } & \text { Standard deviation }\end{array}$

\section{Introduction}

Bacillus anthracis produces two binary toxins associated with the pathogenesis of anthrax [1]. Protective antigen (PA) is an 83-kDa protein responsible for cell binding and target cell translocation of catalytic toxin components lethal factor (LF) and edema factor (EF). Thus, PA is the universal target for 
development of anti-toxin treatments and vaccines since blocking it prevents cellular intoxication. Methods described for detecting PA include ELISA, europium nanoparticle-based immunoassay, time-resolved fluorescence immunoassay [2-5], electro-chemiluminescence, metal-enhanced fluorescence, AlphaLISA, and surface plasmon resonance [6-9]. However, these methods can be lacking in precision, sensitivity, and quantitative accuracy, and in some, their utility has not been verified by matrix testing or application to infection samples.

Detection of PA during infection can be complex as it may exist in many forms. During cellular intoxication, PA83 binds to cell surface receptors CMG2 and TEM8 $[10,11]$, where it is cleaved by furin-like proteases, releasing its $20-\mathrm{kDa}$ amino terminus, leaving $63 \mathrm{kDa}$ (PA63) bound to the cell surface [1]. PA63 forms heptameric and octameric complexes [12, 13], which are capable of binding up to four molecules of the catalytic toxin components, edema factor (EF), and lethal factor (LF) [13, 14]. EF bound to PA is described as edema toxin and LF bound to PA as lethal toxin (LTx). The PA63-EF/ LF complexes are internalized by clathrin-mediated endocytosis [15]. The low $\mathrm{pH}$ within the endosome triggers conformational changes in the PA63 oligomer, leading to poreformation and translocation of EF/LF into the cell cytoplasm [1]. Within the cell, EF, an adenylate cyclase and LF, a zincdependent endoproteinase cause irreversible changes in their known substrates, adenosine tri-phosphate and mitogenactivated protein kinase (MAPKK), respectively $[16,17]$.

Previous studies found that PA83 is activated to PA63 by proteases in the blood $[18,19]$. Serum protease-activated PA63 was shown to bind LF and form fully functional LTx [20]. LTx was also identified in terminal blood of infected rabbits and guinea pigs [20]. None of the PA was found as PA83 $[18,20]$. These findings suggest LTx is a potential diagnostic biomarker and distinct therapeutic target. However, LTx has not been detected or measured prior to the moribund and terminal stages. Thus, until this work, it was not known whether LTx is present in early infection.

We previously described an isotope-dilution (ID) matrixassisted laser-desorption ionization time-of-flight (MALDITOF) mass spectrometry method that quantifies total LF (free LF+LTx) [21]. The method incorporates three steps, antibody capture, LF peptide substrate cleavage, and MS detection of cleaved peptide. These steps each provide a level of specificity and sensitivity and matrix detection limits of $0.005 \mathrm{pg} / \mathrm{mL}$ [21-24].

The utility of total LF measurement was demonstrated in two circumstances. The first was characterization of triphasic toxemia during the course of experimental inhalation anthrax [25]. The second was characterization of toxin clearance during treatment of naturally occurring inhalation anthrax which showed that total LF declined gradually with antibiotic treatment and rapidly with anthrax immune globulin intravenous (AIGIV) anti-toxin treatment [26,27]. AIGIV is composed of immune plasma from individuals immunized with the anthrax vaccine adsorbed $\left(\right.$ BioThrax $\left.^{\circledR}\right)$ [28]. The therapeutic component is predominantly anti-PA IgG which binds PA and associated proteins such as LF and EF, targeting them for removal from circulation through Fc-mediated immune mechanisms. Monitoring LF provides an indirect measurement of toxin clearance since it is not known how much LF is PA associated. An LTx-specific method would provide a direct measure of PA-specific toxin clearance. Importantly, it could also determine the presence of LTx throughout infection and its potential as a therapeutic and diagnostic target.

Here, we describe a three-step method to detect and measure LTx. Anti-PA mAb magnetic beads were used to immunoprecipitate PA (Fig. 1, step 1). Immobilized LTx is reacted
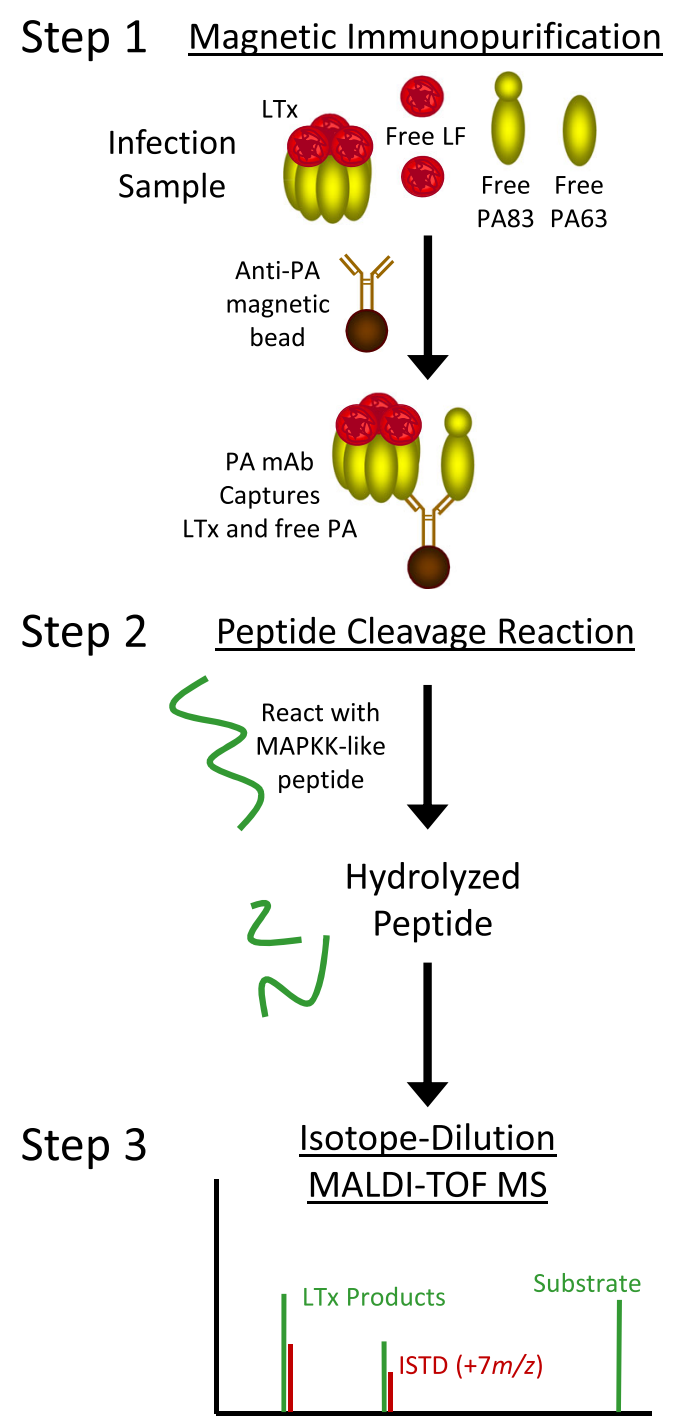

Fig. 1 Schematic of the three-step LTx method. LTx-specific activity is analyzed using anti-PA mAb's on magnetic beads to capture LTx complex (step 1) followed by incubation of LTx on the bead with a MAPKK-like peptide substrate which it hydrolyzes into two distinct smaller peptide products (step 2). The products are detected and quantified by isotopedilution MALDI-TOF MS for a measure of the LTx in a sample (step 3) 
with and hydrolyzes an optimized peptide substrate (step 2). Cleaved peptide products are detected and quantified by MALDI-TOF MS (step 3). This provided measurement of LF that co-purified with activated PA63, quantifying LTx complex. This study describes development, validation, and application of the LTx method. The method was sensitive, specific, and precise and demonstrated for the first time that PA63 as LTx is present in early anthrax.

\section{Materials and methods}

\section{Reagents}

Materials and reagents were obtained from Sigma-Aldrich (St Charles, MO) except where indicated. LF, EF, PA83, and PA63 were obtained from List Biological Laboratories (Campbell, CA). Normal North American (NNA) human ten-donor-pooled plasma and serum and plasma from 100 individual NNA donors were obtained from Interstate Blood Bank (Memphis, TN). AIGIV was obtained from the Division of Strategic National Stockpile, CDC (Atlanta, GA).

\section{Animal care and study protocol}

The inhalation anthrax study in 24 rhesus macaques (Macaca mulatta) was conducted at the Battelle Biomedical Research Center (Columbus, $\mathrm{OH}$ ) as previously described and approved by both Battelle and the Centers for Disease Control and Prevention Institutional Animal Care and Use Committees [25]. This two-part study was approved in 2006 (CDC IACUC protocol no. 1459BOYMONX and Battelle MREF protocol no. 570) and carried out in 2006-2007. Sufficient sample volumes generated from this approved protocol were remaining and used for this study. Animals were challenged with $275 \pm$ $72 \mathrm{LD}_{50}$ aerosolized $B$. anthracis Ames spores by inhalation (target dose $200 \mathrm{LD}_{50}$ ). Whole blood and plasma were collected in EDTA tubes at -30 days and 12, 18, 24, 36, 48, 72, 96 , and $120 \mathrm{~h}$, and serum was collected for five animals as described previously [25]. Plasma/serum was filter sterilized and culture confirmed before shipment. Culture and PCR of the protective antigen gene ( $\operatorname{pag} A$ ) were described previously [25]. Total LF and LTx analysis was determined in two animals, $16 \mathrm{~N}$ and $89 \mathrm{~N}$, over the course of infection. An additional 22 post-spore exposure samples were analyzed. Pre- and post-antibiotic treatment samples were available for six animals treated with Ciprofloxacin at $20 \mathrm{mg} / \mathrm{kg}$ twice daily for 14 days in surviving animals. Treatment commenced at $48 \mathrm{~h}$ post-challenge in four animals and at $72 \mathrm{~h}$ in two. Four of six survived.
Magnetic antibody beads

Anti-PA mouse monoclonal antibodies (mAb) AVR1046 and two anti-LF mAb (AVR1674 and AVR1675) were linked to Tosyl-activated magnetic beads (MB; Life Technologies, Grand Island, NY) according to the manufacturer's instructions yielding anti-PA and dual anti-LF MBs. Kingfisher 96 magnetic particle processor (Thermo-Fisher Scientific, Waltham, MA) was used for all MB handling.

\section{Antibody specificity}

Specificity of anti-PA and anti-LF MBs was demonstrated for LTx, LF, and PA. PA63/LF were mixed at a $w / w$ ratio of 10:1 to form LTx complex. PA83 and LF were mixed as a noncomplexed control. Mixtures were incubated at room temperature (RT) for $30 \mathrm{~min}$. LF, PA63, PA83, LF/PA63, and LF/ PA 83 at $0.5 \mu \mathrm{g}$ LF and $5 \mu \mathrm{g}$ PA83 or PA63 were immunoprecipitated with anti-LF and anti-PA MBs, eluted with $50 \%$ acetonitrile, $2 \mathrm{mM} \mathrm{HCl}$ for $1 \mathrm{~min}$, dried by centrifugal evaporation, reconstituted in sample buffer, analyzed by 5-14 \% SDS-polyacrylamide gel electrophoresis (PAGE; Life Technologies), and visualized by silver stain (SS; Protea Biosciences, Morgantown, WV).

\section{Lethal toxin standard preparation and characterization}

LTx was formed by mixing PA63 and LF at $w / w$ ratios of $0: 1$ to 60:1 PA63/LF, incubating at RT for $30 \mathrm{~min}$. Mixtures were analyzed for free LF levels by non-denaturing PAGE (Life Tech) and SS. A ratio of 50:1 adsorbed the maximum amount of LF. The final LTx standard material was similarly prepared with $25 \mu \mathrm{g}$ PA63/0.5 $\mu \mathrm{g} \mathrm{LF}$ for $500 \mathrm{ng} / \mu \mathrm{L}$ PA63 and $10 \mathrm{ng} /$ $\mu \mathrm{L}$ LF as LTx, then diluted as described below to make standard and quality control materials.

The LTx standard material was analyzed by non-denaturing PAGE to quantify the "free" LF and correct standards. Gel lanes contained $7.5 \mu \mathrm{g}$ PA63, 25, 12.5, 6.25, and $3.125 \mathrm{ng}$ LF and the LTx standard material with $150 \mathrm{ng}$ LF and $7.5 \mu \mathrm{g}$ PA63 to visualize and quantify the small amount of unbound LF. The gel was scanned and bands intensities quantified (Softmax Pro, Molecular Devices, Sunnydale, CA). Free LF intensities were fitted to a linear regression $\left(r^{2}=0.996\right)$, and free LF in the LTx lane was calculated from the linear regression.

The qualitative efficiency of anti-PA purification of the LTx standard material in plasma in the presence of the excess PA63 was determined by comparison with anti-LF purification. The LTx standard material at 100, 50, 25, and $12.5 \mathrm{ng}$ LF and 50 times PA63 each in plasma sample were immunoprecipitated by anti-PA and anti-LF MBs and eluted and analyzed by SDS-PAGE/SS. 
Standard and quality control (QC) materials in plasma were prepared from the characterized material with free LF corrected values of 24.3 to $0.0025 \mathrm{ng} / \mathrm{mL}$ and three QCs with $5.82 \mathrm{ng} / \mathrm{mL}$ (QCH), $0.582 \mathrm{ng} / \mathrm{mL}(\mathrm{QCM})$, and $0.0582 \mathrm{ng} / \mathrm{mL}$ (QCL) LTx.

\section{LTx quantification}

For LTx analysis, $50 \mu \mathrm{L}$ of sample was diluted 1:10 in $450 \mu \mathrm{L}$ phosphate-buffered saline with $0.05 \%$ Tween20 (PBST), mixed with $6.25 \mu \mathrm{L}$ anti-PA-MBs for $1 \mathrm{~h}$, washed two times 2 min each in $1.0 \mathrm{~mL}$ PBST, then in 200 and $100 \mu \mathrm{L} \mathrm{dH}_{2} \mathrm{O}$ for $1 \mathrm{~min}$ each, resuspended in $30 \mu \mathrm{L}$ reaction buffer with the peptide substrate and reacted for 2 and $18 \mathrm{~h}$ at $37^{\circ} \mathrm{C}$. After the 2-h reaction, $3 \mu \mathrm{L}$ of sample was mixed with $\alpha$-cyano-4hydroxycinnamic acid (CHCA) at $5 \mathrm{mg} / \mathrm{mL}$ in $50 \%$ acetonitrile, $0.1 \%$ trifluoroacetic acid, and $1 \mathrm{mM}$ ammonium phosphate (CHCA-MALDI matrix) and isotopic internal standard peptides (ISTD) and analyzed by ID-MALDI-TOF/MS as described previously $[22,23]$. The remaining reaction was incubated for analysis at $18 \mathrm{~h}$. The LTx cleaved peptide MS peak area/ISTD peak area (area ratio) was plotted versus LTx standard concentration with dual $\log _{10}$ transformation and 5PL robust quantification.

\section{LTx method validation}

Recovery for this method compared activities for $0.5 \mathrm{ng} \mathrm{LF}$ and LTx (0.5 ng LF+1 ng PA63) both without capture and with anti-PA purification. Precision, accuracy, and LOD were determined from 25 standards/QC analyses with precision as the coefficient of variation $(\% \mathrm{CV})$ and accuracy as the percent error (\%error). Acceptable criteria described previously [29] place accuracy at $\leq 20 \%$ error and precision at $\leq 20 \% \mathrm{CV}$ except at the upper $(\leq 15 \%)$ and lower limit of quantitation $(<25 \%)$. Linearity was acceptable with a slope $\geq 0.8$ and $\leq 1.2$ and an $r$-squared $\geq 0.85$. Quantifiable ranges were determined using these criteria for both 2- and 18-h reactions. Limits of detection (LOD) were determined for the method including all steps (sample preparation, enzymatic reaction, and MALDITOF analysis) by plotting standard deviations (SD) versus concentration for the plasma blank and three low standards, one above, one near, and one below the estimated LOD for 30 runs. The $y$-intercept and slope from the linear regression, the $\mathrm{SD}$, and mean of the blank $\left(\mathrm{SD}_{\mathrm{b}}\right.$ and mean $\left._{\mathrm{b}}\right)$ were used to calculate the LOD concentration as follows [30]:

$\operatorname{Conc}_{\mathrm{LOD}}=\left(\operatorname{mean}_{\mathrm{b}}+1.645\left(s_{\mathrm{b}}+\right.\right.$ int $\left.)\right) /(1-1.645($ slope $))$

where $\mathrm{b}$ is blank, $s$ is standard deviation, and int is $y$-intercept.

Specificity was assessed from 100 individual NNA plasma samples and 41 archived human serum samples that included elderly Argentinian's, children from San Diego without routine immunizations, and other infections (Staphylococcus aureus, Legionella pneumophila, Chlamydophila pneumoniae). Sensitivity was assessed for samples from 24 rhesus macaques (19 plasma collected, 5 serum collected) with inhalation anthrax, and in samples from three inhalation anthrax cases (CDC IRB Protocol no. 5343.0, Use of Residual Human Specimens for Laboratory Diagnostic Research) [26, $27,31]$. Samples were analyzed with two or more replicates at one or more dilutions for both 2- and 18-h reactions. Lowerlevel samples requiring higher sample volumes were analyzed singly due to limited sample volumes. For these, means were from both 2- and 18-h results.

Accuracy was assessed for plasma samples with 7.5, 0.75, and $0.075 \mathrm{ng} / \mathrm{mL}$ LTx co-spiked with PA83, LF, and EF at $50 \mathrm{ng} / \mathrm{mL}$ each, analyzed in triplicate. For matrix accuracy, serum and plasma from five individual donors each were spiked with LTx at $2.5 \mathrm{ng} / \mathrm{mL}$ and analyzed in duplicate. Matrix-dependent activation of PA83 to PA63 and formation of LTx was assessed using ten-donor pooled serum and plasma spiked with either $5 \mathrm{ng} / \mathrm{mL}$ PA83 or PA63 and then $2.5 \mathrm{ng} /$ $\mathrm{mL} \mathrm{LF}$, incubated for $1 \mathrm{~h}$ then analyzed for LTx.

For utility with anthrax therapeutics, AIG interference was assessed by spiking AIG at an equivalent of $200 \mu \mathrm{g} / \mathrm{mL}$ antiPA IgG into all 15 standards, plasma blank, and QC samples over the entire range from 24.3 to $0.0024 \mathrm{ng} / \mathrm{mL}$. These were prepared, spiked, and analyzed, on two separate days alongside control (no AIG) standards/blank/QCs spiked with PBS instead of AIG. A clinical anthrax sample with previously quantified LTx of $88 \mathrm{ng} / \mathrm{mL}$ was analyzed in triplicate without and with AIG spiked at $200 \mu \mathrm{g} / \mathrm{mL}$ anti-PA IgG. After spiking, samples were mixed for $1 \mathrm{~h}$ then analyzed for LTx. Interferences from antimicrobial treatment were assessed by analyzing LTx before and after treatment for animal and clinical inhalation anthrax described above.

Data reporting and statistical analyses

Analyses and formulas were described above where appropriate. Standard calculations, means, standard deviations, and linear regressions were performed in excel. Custom visual basic programs calculated values for LTx from the 5PL regressions. LTx levels were reported in nanograms per milliliter. Grading for culture results were described previously [25].

\section{Results}

Method overview

As described in the "Introduction," the method has three primary steps, magnetic immunoprecipitation, substrate cleavage reaction, and MALDI-TOF MS quantification. The following results include characterization of LTx complex formation 
from PA63 and LF for standards material, characterization of the ability of the magnetic-bead-coated antibodies to selectively purify LTx, LTx reaction with substrate, and MALDITOF MS quantification of LTx reaction products.

\section{LTx standard preparation and characterization}

Since the measurement of LTx relies on detection of LF activity in LTx complex, the aim was to create standards with a minimum of free LF. Activated PA63 exists as a heptamer/ octamer that binds up to four LF molecules forming the LTx complex, with optimal molecular ratios represented by a weight/weight ratio of 1.5:1 PA63/LF [12, 13, 32]. However, optimum binding of LF in these standards materials required 50:1 PA63/LF as visualized by non-denaturing gel electrophoresis and higher PA63 levels did not bind more LF (not shown). PA63 alone with multimer and monomer (Fig. 2a, lane 1) was compared with the LTx mixture (lane 6) which shows two additional primary bands that migrate lower than the non-complexed multimer. These bands represent the LTx complex. A significant amount of PA63 multimer and monomer remains uncomplexed. The free LF band in lane 6 was visible, and its gel-band intensity was quantified against a linear regression derived from the LF-only lanes $2-5$. The amount of free LF in the standards was quantified at $4.56 \mathrm{ng}$, which was $3 \%$ of the total $150 \mathrm{ng}$ LF loaded (Fig. 2a). LTx standard concentrations were corrected by subtracting the $3 \%$ free LF.

Magnetic antibody bead specificity

Antibody specificities demonstrated by magnetic immunoprecipitation of individual toxin components showed that anti-LF purified LF but not PA83 or PA63 and anti-PA purified PA83 and PA63 but not LF (Fig. 2b). Specificity for pre-formed LTx complex was observed for both anti-PA and anti-LF since both PA63 and LF bands were extracted and present (Fig. 2c). With PA83+ LF, complex was not formed and anti-LF extracted LF but not PA83 and anti-PA extracted PA83 but not LF. In all, the data support the individual specificities of anti-PA and anti-LF mAbs for LF and PA and the ability of both to purify LTx complex.

Since LTx standards were prepared with 50 times more PA63 than LF, it was determined whether the excess PA63 interfered with purification of LTx. Immunoprecipitation of 100 to $12.5 \mathrm{ng}$ LTx standard material from plasma showed that the amount of LF in complex extracted by anti-PA and anti-LF MBs were visually similar (Fig. 2d). Additionally, the PA63 bands purified by anti-PA were more intense (lanes 5-
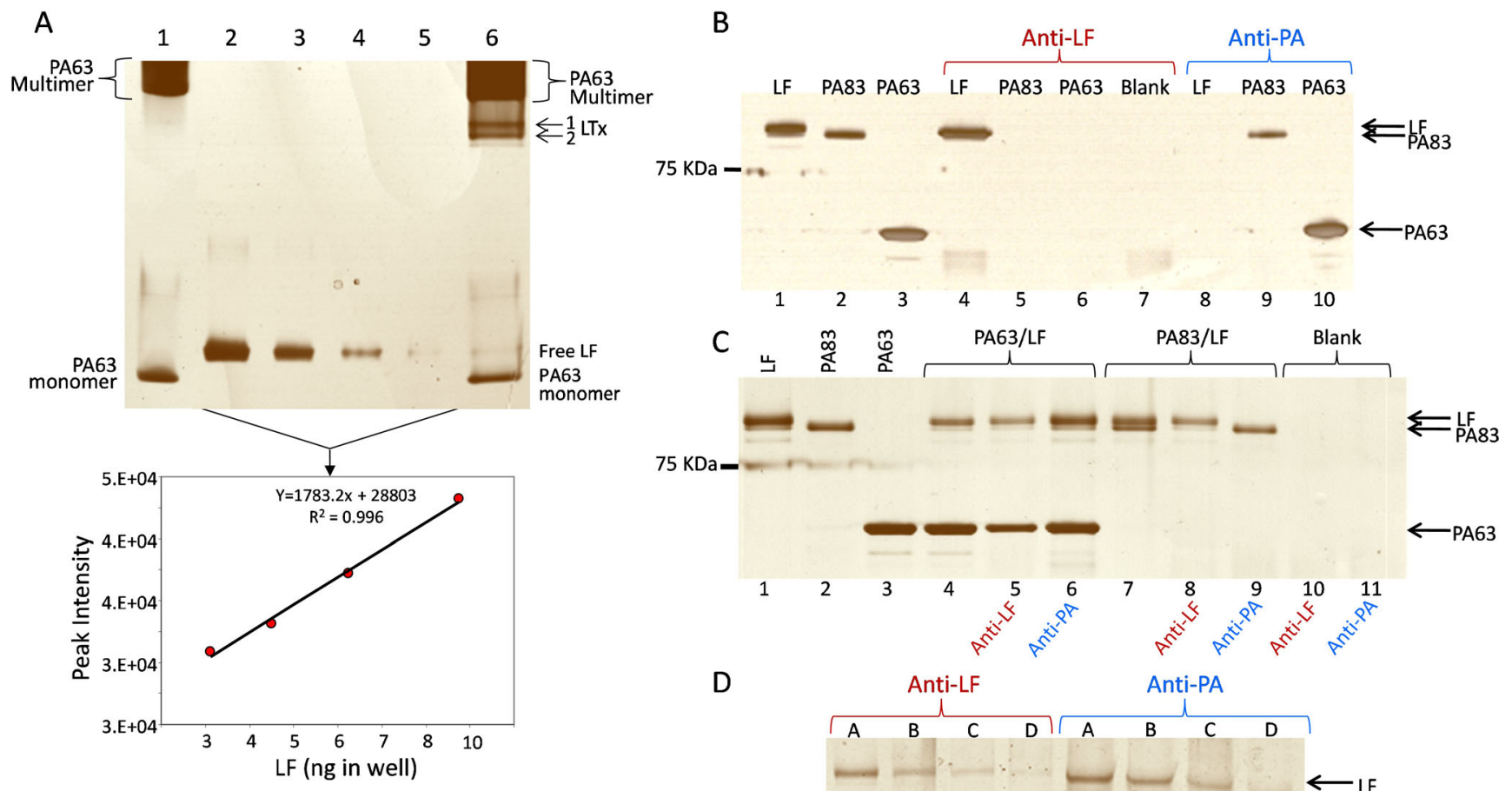

Fig. 2 LTx and antibody characterization. LTx for standard material was analyzed by non-denaturing gel electrophoresis. The gel was scanned, LF band intensities were quantified, and the amount of free LF was estimated from the linear curve (a). Specificity of anti-LF and anti-PA for LF, PA83,

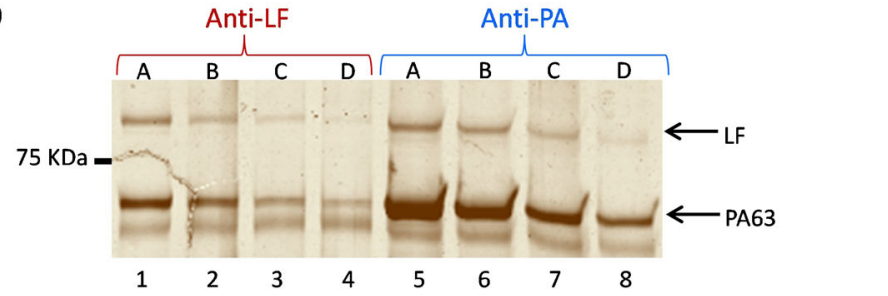

and PA63 alone (b), PA63/LF (LTx) and PA83/LF (c), and LTx standards material; $A 100 \mathrm{ng} \mathrm{LTx}, B 50 \mathrm{ng}, C 25 \mathrm{ng}$, and $D 12.5 \mathrm{ng}$ in plasma (d) was assessed by magnetic immunoprecipitation and SDS-PAGE 
8). Combined, this indicated that anti-PA levels on the beads were sufficient to capture LTx and excess non-complexed PA63. Thus, PA did not saturate the beads at these levels. Furthermore, much less material is used for LTx calibrators. The highest standard is at $24 \mathrm{ng} / \mathrm{mL}$ with only $50 \mu \mathrm{L}$ used for analysis. In summary, anti-PA was suitable for purification of LTx and the excess PA63 did not interfere with its purification.

Catalytic activity and quantification of LTx

LTx activity is quantified by cleavage of a peptide substrate yielding two products (Fig. 3a). MALDI-TOF MS of a representative positive reaction show the substrate at $2804.2 \mathrm{~m} / \mathrm{z}$, two products at 1232.8 and $1589.8 \mathrm{~m} / \mathrm{z}$ and ISTD peptide peaks at 1239.8 and $1596.8 \mathrm{~m} / \mathrm{z}$, respectively (Fig. 3b). Narrowing the $x$-axis shows the isotopic detail of the CTproduct and ISTD. The CT isotopic area divided by the CTISTD area yields the area ratio that is directly proportional to the amount of LTx present. For a negative reaction processed from the plasma blank only the substrate and ISTD peaks are present (Fig. 3c). Area ratios were plotted versus concentration and both axes were $\log _{10}$ transformed generating a sigmoidal curve. Quantitative accuracy was optimal using 5PL regression with robust weighting. Custom visual basic programs integrated MS peaks and applied the 5PL fits to quantify standards and samples (Fig. 3d).
A Substrate
SKARRKKVYPYPXENFPPSTARPT 2804.2
NT product SKARRKKVYP

\section{YPXENFPPSTARPT 1589.8}
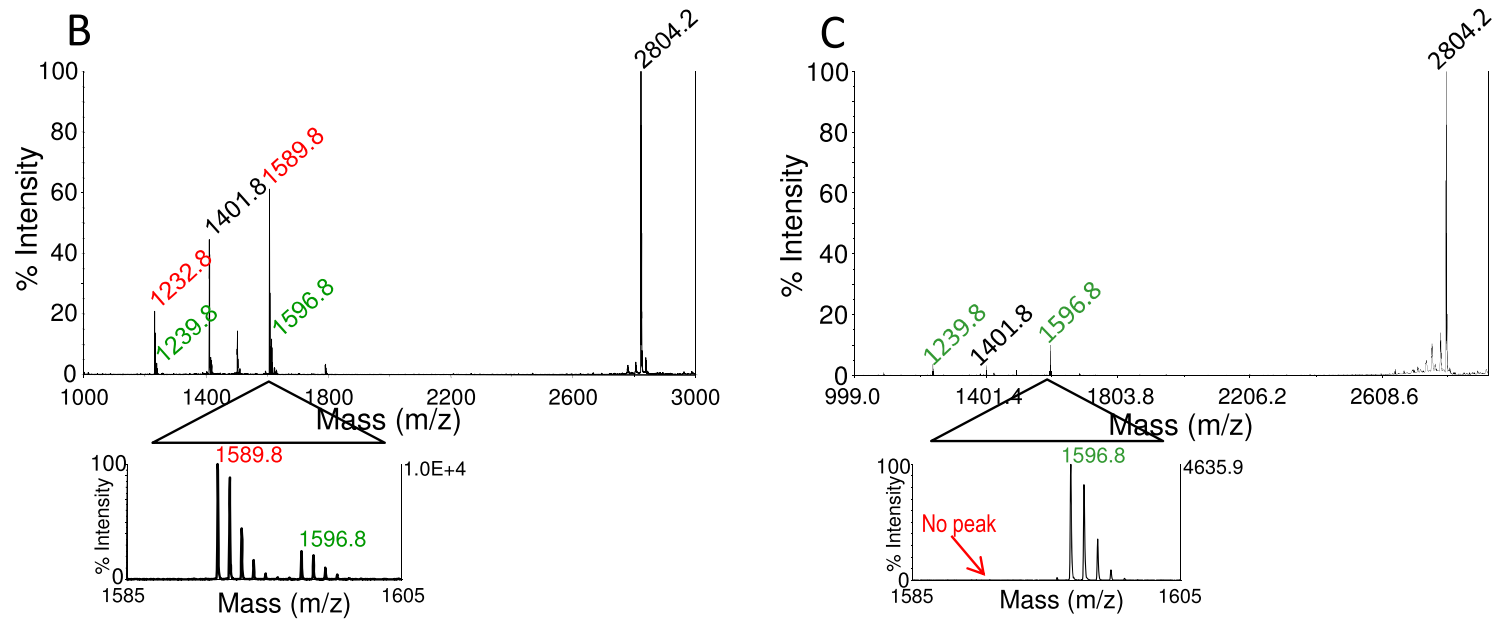

D

$E$
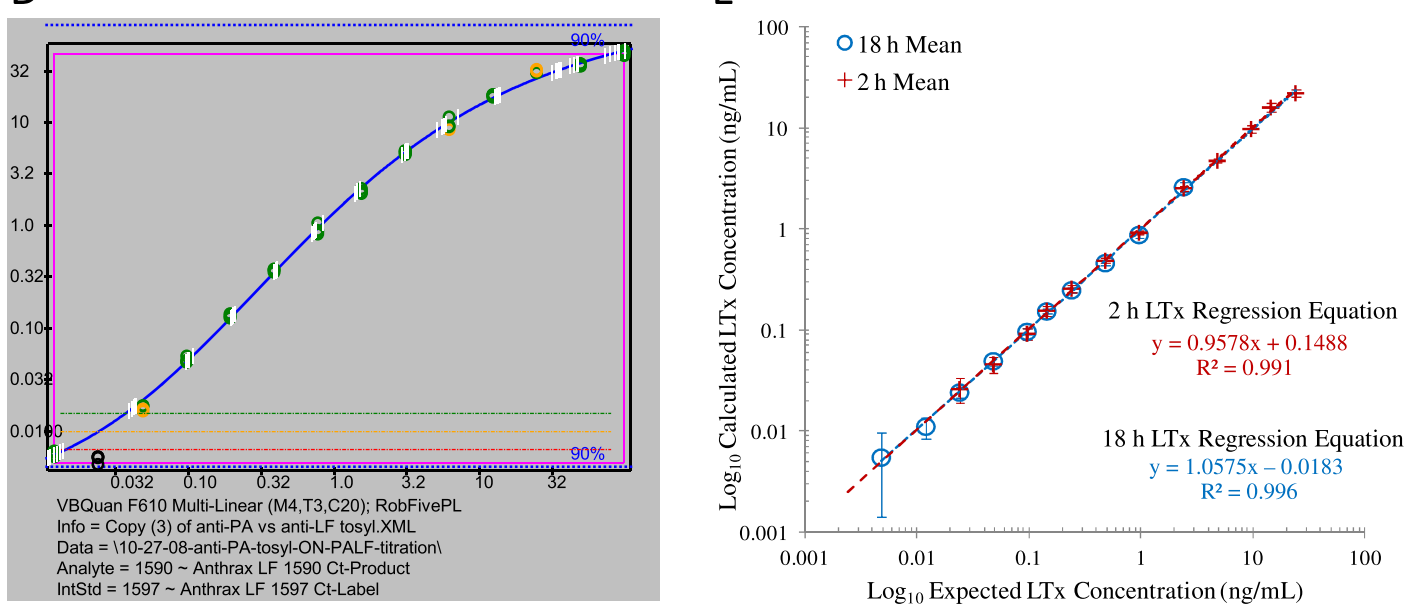

Fig. 3 ID-MALDI-TOF MS of LTx catalytic activity and quantification. The LTx substrate peptide sequence shown in standard amino acid codes except for non-standard amino acid norleucine depicted as an $X$. Magnetic-affinity-purified LTx hydrolyzes the LF peptide substrate between the $\mathrm{p} 1$ proline and $\mathrm{p} 1$ ' tyrosine, yielding two smaller peptides (a). The cleavage reaction is mixed with ISTD peptides $(+7 \mathrm{~m} / \mathrm{z})$ and analyzed by ID-MALDI-TOF MS. Spectra show a positive reaction

with LTx in plasma (b) and negative reaction without LTx in plasma (c). Output for the 5PL regression generated by custom visual basic software for an 18-h reaction. The orange line indicates the estimated LOD (three times the plasma blank area ratio) for each analysis (c). Linearity of LTx quantification for 25 independent analyses of standards levels showing means and SD (error bars) for 2- and 18-h reactions (e) 


\section{LTx method validation}

Performance criteria were determined with 25 independent analyses of LTx standards/QC sets. Means, standard deviations (SD), \%error, and \%CV are shown for each level and reaction time (Table 1). Recommended accuracy of $\leq 20 \%$ error and precision of $\leq 20$ and $\leq 15 \% \mathrm{CV}$ for the ULOQ and $\leq 25 \% \mathrm{CV}$ for the LLOQ defined the quantitative range [29, 33]. Interday accuracy for 2-h reactions was $0.1-9.8 \%$ error from $\mathrm{S} 1$ to $\mathrm{S} 12 \mathrm{ng} / \mathrm{mL}$ and precision was $3.7-14 \% \mathrm{CV}$ from $\mathrm{S} 1$ to $\mathrm{S} 10 . \mathrm{S} 11$, at $24 \% \mathrm{CV}$, met the recommendation for LLOQ. Therefore, the optimal quantitative range for 2-h reactions was S1-S11, with the LLOQ at $0.049 \mathrm{ng} / \mathrm{mL}$. For $18-\mathrm{h}$ reactions, accuracy and precision, respectively, were $0.2-$ $13 \%$ error for S5-S14 and 4.2-12 \%CV for S5-S12. S13 $(0.012 \mathrm{ng} / \mathrm{mL})$ with $25 \% \mathrm{CV}$, was acceptable for the $18 \mathrm{-h}$ LLOQ. The detection limit calculated from 30 independent analyses of low plasma standards was $0.033 \mathrm{ng} / \mathrm{mL}$ and $0.0074 \mathrm{ng} / \mathrm{mL}$ for the 2 - and $18-\mathrm{h}$ reaction times, respectively. The calculated mean concentrations plotted versus expected concentration showed linear regressions with slopes near 1 , 0.96 for 2 -h, and 1.06 for 18 -h reactions, and $r^{2} \geq 0.991$ for both 2- and 18-h reactions (Fig. 3e). Mean values for 2- and 18-h reactions were precisely overlaid at the universal levels. Precision from 25 independent QC analyses was 9.9 and $7.2 \%$, respectively, for QCH and QCM for the 2-h reaction time and 6.3 and $9.0 \%$, respectively for QCM and QCL for the 18-h reaction time (Table 1).

Extraction recoveries could not be properly assessed because activity of LF was higher when bound by PA63 and anti-PA-MB. Area ratios obtained from reactions were much lower for $0.5 \mathrm{ng} L F$ alone (1.4 \pm 0.02$)$, compared with $0.5 \mathrm{ng}$ LF in complex as LTx $(20 \pm 1)$ and LTx extracted by anti-PA (22 \pm 0.3$)$. This implied recoveries of $>100 \%$.

Specificity was $100 \%$. There were no false positives for 100 plasma samples from North American donors and 41 serum samples from other infections. Sensitivity was $100 \%$ with LTx measured in all infected subjects, three documented inhalation anthrax cases, and 24 rhesus macaques [26, 27, 31, 34].

There was no observable interference from other anthrax toxins and accuracy was good with low error of $0.8-12.7 \%$ for samples covering three orders of magnitude (Table 2). This included $50 \mathrm{ng}$ PA83 and EF toxins, 667-fold excess at the lowest LTx level. Inclusion of $50 \mathrm{ng} / \mathrm{mL}$ free LF contributed to higher LTx as expected since it was able to bind the excess free PA63 in the LTx sample.
Table 1 Mean, SD, accuracy (\% error), precision ( $\% \mathrm{CV})$, and analytical ranges (bold font) for LTx standards, plasma blank (PBL), and quality control samples (QCs), for 2- and 18-h reactions analyzed over 25 days. Standard levels with $\leq 20 \%$ error, $\leq 20 \% \mathrm{CV}$ for middle range, $\leq 15 \% \mathrm{CV}$ (ULOQ), and $\leq 25 \% \mathrm{CV}$ (LLOQ) are indicated in italics. Limits of detection (LOD) were calculated as described

\begin{tabular}{|c|c|c|c|c|c|c|c|c|c|}
\hline \multirow[t]{2}{*}{ LTx standard } & \multirow[t]{2}{*}{ Expected (ng/mL) } & \multicolumn{4}{|l|}{ 2-h reaction } & \multicolumn{4}{|l|}{18 -h reactions } \\
\hline & & Observed (ng/mL) & SD & $\%$ error & CV (\%) & Observed (ng/mL) & SD & $\%$ error & $\mathrm{CV}(\%)$ \\
\hline S1 & 24.3 & 22.9 & 1.78 & 5.4 & 7.8 & 14.0 & 4.3 & 42 & 31 \\
\hline S2 & 14.6 & 16.0 & 1.47 & 9.8 & 9.2 & 12.9 & 1.9 & 11 & 15 \\
\hline S3 & 9.7 & 9.55 & 0.56 & 1.5 & 5.9 & 11.6 & 2.6 & 20 & 23 \\
\hline S4 & 4.85 & 4.81 & 0.24 & 0.9 & 4.9 & 5.89 & 1.2 & 21 & 20 \\
\hline S5 & 2.43 & 2.52 & 0.093 & 4.1 & 3.7 & 2.63 & 0.31 & 8.3 & 12 \\
\hline S6 & 0.97 & 0.932 & 0.042 & 3.9 & 4.5 & 0.890 & 0.051 & 8.2 & 5.7 \\
\hline S7 & 0.485 & 0.485 & 0.018 & 0.1 & 3.7 & 0.462 & 0.019 & 4.8 & 4.2 \\
\hline S8 & 0.243 & 0.254 & 0.019 & 4.8 & 7.4 & 0.249 & 0.015 & 2.7 & 6.1 \\
\hline S9 & 0.146 & 0.156 & 0.016 & 7.0 & 11 & 0.155 & 0.010 & 6.7 & 6.4 \\
\hline S10 & 0.097 & 0.093 & 0.013 & 4.0 & 14 & 0.097 & 0.0071 & 0.2 & 7.3 \\
\hline S11 & 0.049 & 0.045 & 0.011 & 7.2 & 24 & 0.050 & 0.0050 & 2.1 & 10 \\
\hline 2-h LOD & & 0.033 & NA & NA & NA & & & & \\
\hline S12 & 0.024 & 0.024 & 0.0083 & 0.6 & 34 & 0.024 & 0.0029 & 0.4 & 12 \\
\hline S13 & 0.012 & 0.014 & 0.0067 & 18 & 47 & 0.011 & 0.0027 & 13 & 25 \\
\hline 18-h LOD & & & & & & 0.0075 & NA & NA & NA \\
\hline S14 & 0.0049 & 0.009 & 0.0078 & 83 & 88 & 0.0054 & 0.0039 & 12 & 72 \\
\hline S15 & 0.0024 & 0.007 & 0.0074 & 185 & 107 & 0.0035 & 0.0014 & 45 & 39 \\
\hline PBL & 0 & 0.0019 & 0.0041 & NA & 213 & 0.00037 & 0.0010 & NA & 278 \\
\hline QCH & 5.82 & 5.29 & 0.52 & 9.1 & 9.9 & NA & NA & NA & NA \\
\hline QCM & 0.582 & 0.547 & 0.039 & 6.0 & 7.2 & 0.528 & 0.033 & 9.3 & 6.3 \\
\hline QCL & 0.0582 & NA & NA & NA & NA & 0.055 & 0.005 & 5.3 & 9.0 \\
\hline
\end{tabular}


Table 2 Accuracy (\%error) of LTx quantitation in the presence of other anthrax toxins, PA83, LF, and EF

\begin{tabular}{|c|c|c|c|c|c|c|c|c|}
\hline & LTx (ng/mL) & PA83 (ng/mL) & $\mathrm{LF}(\mathrm{ng} / \mathrm{mL})$ & $\mathrm{EF}(\mathrm{ng} / \mathrm{mL})$ & Mean \pm SD (2 h) & Mean \pm SD $(18$ h) & \%error (2 h) & \%error (18 h) \\
\hline LTx-1 & 7.5 & - & - & - & $8.2 \pm 0.31$ & & 8.5 & \\
\hline LTx-2 & 7.5 & 50 & - & - & $8.4 \pm 0.17$ & & 11.5 & \\
\hline LTx-3 & 7.5 & - & 50 & - & $22 \pm 0.19$ & & NA & \\
\hline LTx-4 & 7.5 & - & - & 50 & $7.7 \pm 0.15$ & & 3.3 & \\
\hline LTx-5 & 0.75 & - & - & - & $0.80 \pm 0.022$ & $0.71 \pm 0.023$ & 6.1 & 5.9 \\
\hline LTx-6 & 0.75 & 50 & - & - & $0.84 \pm 0.011$ & $0.74 \pm 0.011$ & 12.3 & 0.8 \\
\hline LTx-7 & 0.75 & - & 50 & - & $8.5 \pm 0.12$ & $8.2 \pm 0.38$ & NA & NA \\
\hline LTx-8 & 0.75 & - & - & 50 & $0.76 \pm 0.03$ & $0.66 \pm 0.021$ & 1.2 & 11.8 \\
\hline LTx-9 & 0.075 & - & - & - & $<\mathrm{LOD}$ & $0.083 \pm 0.0035$ & & 9.9 \\
\hline LTx-10 & 0.075 & 50 & - & - & $<\mathrm{LOD}$ & $0.085 \pm 0.0012$ & & 12.7 \\
\hline LTx-11 & 0.075 & - & 50 & - & $0.98 \pm 0.018$ & $0.86 \pm 0.032$ & & NA \\
\hline LTx-12 & 0.075 & - & - & 50 & $<\mathrm{LOD}$ & $0.076 \pm 0.0022$ & & 1.8 \\
\hline
\end{tabular}

Matrix-dependent accuracy was assessed because serum and plasma samples may have different components released during processing that influence LTx activity. LTx levels measured in the serum samples $(2.6 \pm 0.28 \mathrm{ng} / \mathrm{mL})$ were similar to plasma $(2.4 \pm 0.17 \mathrm{ng} / \mathrm{mL})$ for a 2 -h reaction but were higher in serum $(3.1 \pm 0.42 \mathrm{ng} / \mathrm{mL})$ than plasma $(2.6 \pm 0.31 \mathrm{ng} / \mathrm{mL})$ after $18 \mathrm{~h}$. The mean \%error in calculated value from the expected $2.5 \mathrm{ng} / \mathrm{mL}$ for 2 and $18 \mathrm{~h}$ combined was lower for plasma samples at $7.7 \pm 6.8 \%$ compared with serum at $17 \pm 14 \%$ suggesting that factors present in serum may reduce accuracy and produce more variability in LTx activity.

Serum and plasma matrices were also evaluated for artificial cleavage of PA83 to PA63 by serum clotting cascade proteases which would form LTx in the presence of LF. No LTx was detected in serum or plasma spiked with PA83 and $\mathrm{LF}$ at 5 and $2.5 \mathrm{ng} / \mathrm{mL}$, respectively. In contrast, PA63 and LF spiked together resulted in significant formation of complex in both serum $(1.8 \pm 0.16 \mathrm{ng} / \mathrm{mL})$ and plasma $(2.0 \pm 0.074 \mathrm{ng} /$ $\mathrm{mL}$ ), with plasma LTx measured higher than serum. This demonstrated that no measureable conversion of PA83 to PA63 occurred in serum or plasma under these conditions.

The interference of AIG (Cangene Corp, Canada) on LTx quantification was assessed by spiking standards, QCs, plasma blank, and an infection sample with therapeutic levels of AIG (200 $\mu \mathrm{g} / \mathrm{mL}$ anti-PA IgG). LTx measured was lower with AIG compared with samples without AIG (Table 3). Overall, accuracy was high with only $9.4 \pm 8.0 \%$ error without AIG and was lower with AIG at $40 \pm 20 \%$ error. However, accuracy was better for the higher AIG-spiked standards, 11-24\% error (S2-S4) and was reduced in lower standards and all QCs, ranging from 34 to $70 \%$ error (S5-S12, QCH, M, L). LTx with AIG was detected as low as the $\mathrm{S} 12$ standard $(0.024 \mathrm{ng} / \mathrm{mL})$, though it was quantified lower at $0.014 \pm 0.007 \mathrm{ng} / \mathrm{mL}$. LTx in a clinical sample was similar at $93 \pm 4.7 \mathrm{ng} / \mathrm{mL}$ with AIG compared with that without AIG $(88 \pm 2.6 \mathrm{ng} / \mathrm{mL})$, indicating no interference by AIG in this sample (Table 3 ).
Interference of LTx detection by antimicrobial treatment was assessed in six rhesus macaques and three clinical cases [26, 27, 31, 34]. Pre- and post-antimicrobial treatment LTx levels were determined for all subjects except one for which a pre-treatment sample was not available (Table 4). Pretreatment LTx levels were 2.3-280 ng/mL. LTx was detected post-treatment in all subjects. Latest post-treatment LTx was low in the survivors (2-8 days post-treatment), at $0.012-$ $0.096 \mathrm{ng} / \mathrm{mL}$, and was higher in two non-surviving rhesus macaques, 8.6 and $8.7 \mathrm{ng} / \mathrm{mL}$. In animal R050003, the higher post-treatment LTx appeared to be due to a short treatment interval $(36 \mathrm{~h})$ and in animal 04208 to higher pre-treatment LTx $(280 \mathrm{ng} / \mathrm{mL})$.

\section{LTx detection in rhesus macaques during inhalation anthrax}

Two female rhesus macaques, $16 \mathrm{~N}$ and $89 \mathrm{~N}$, were exposed by aerosol inhalation to 248 and $264 \mathrm{LD}_{50}$ B. anthracis Ames spores, respectively. Both animals survived 5 days post-exposure. Both were positive for culture, pagA PCR, and LTx by $36 \mathrm{~h}$ and remained positive (Table 5). Earliest LTx levels were low, 0.24 and $0.10 \mathrm{ng} / \mathrm{mL}$ for $16 \mathrm{~N}$ and $89 \mathrm{~N}$, respectively. Animal $16 \mathrm{~N}$ increased almost 100-fold from 36 to $72 \mathrm{~h}$ to $21 \mathrm{ng} /$ $\mathrm{mL}$, declined to $5.4 \mathrm{ng} / \mathrm{mL}$ at $96 \mathrm{~h}$, then increased $>2000$-fold at $120 \mathrm{~h}$ to $12,100 \mathrm{ng} / \mathrm{mL}$. Animal $89 \mathrm{~N}$ increased 10 -fold from 36 to $48 \mathrm{~h}$ to $1.02 \mathrm{ng} / \mathrm{mL}$, remained stable at $72 \mathrm{~h}$, increased 10 fold at $96 \mathrm{~h}(11.5 \mathrm{ng} / \mathrm{mL})$, then 100 -fold at $120 \mathrm{~h}(1150 \mathrm{ng} / \mathrm{mL})$.

Comparison of LTx with total LF (free LF+LTx) showed that LF was first detected in animal $16 \mathrm{~N}$ and $89 \mathrm{~N}$ at 18 and $24 \mathrm{~h}$ post-exposure, respectively, 18 and $12 \mathrm{~h}$ prior to LTx, culture, and PCR (Table 5). At 36 h, LF was 7.5-22 times higher than LTx, demonstrating a majority of free LF in the earliest stages of infection. However, at the terminal stage, LTx increased and was $100 \%$ of the total LF for $16 \mathrm{~N}$ and $60 \%$ for $89 \mathrm{~N}$. In summary, LTx was detected early and increased to become the dominant form of LF in late infection. 
Table 3 Effect of AIG $(200 \mu \mathrm{g} / \mathrm{mL})$ on LTx quantification

\begin{tabular}{|c|c|c|c|c|c|c|c|}
\hline \multirow[t]{2}{*}{ Level } & \multirow[t]{2}{*}{ Expected (ng/mL) } & \multicolumn{3}{|l|}{ No AIG } & \multicolumn{3}{|l|}{ AIG } \\
\hline & & LTx $(\mathrm{ng} / \mathrm{mL})$ & SD & \%error & LTx (ng/mL) & SD & $\%$ error \\
\hline S1 & 24.3 & 22 & 5.20 & 9.0 & 17 & 0.79 & 32 \\
\hline S2 & 14.6 & 13 & 2.84 & 10 & 13 & 2.3 & 11 \\
\hline $\mathrm{S} 3$ & 9.7 & 11 & 1.34 & 16 & 8.5 & 2.8 & 12 \\
\hline S4 & 4.85 & 4.1 & 1.68 & 17 & 3.7 & 1.8 & 24 \\
\hline S5 & 2.43 & 2.6 & 0.108 & 8.1 & 1.6 & 0.68 & 35 \\
\hline S6 & 0.97 & 0.87 & 0.008 & 10 & 0.41 & 0.033 & 57 \\
\hline S7 & 0.485 & 0.48 & 0.014 & 1.9 & 0.20 & 0.014 & 58 \\
\hline S8 & 0.243 & 0.26 & 0.020 & 5.3 & 0.14 & 0.042 & 41 \\
\hline S9 & 0.146 & 0.16 & 0.030 & 11 & 0.096 & 0.029 & 34 \\
\hline S10 & 0.097 & 0.099 & 0.0035 & 2.5 & 0.042 & 0.012 & 57 \\
\hline S11 & 0.049 & 0.049 & 0.0060 & 0.03 & 0.016 & 0.0080 & 68 \\
\hline $\mathrm{S} 12$ & 0.024 & 0.018 & 0.0008 & 24 & 0.014 & 0.0071 & 42 \\
\hline $\mathrm{S} 13$ & 0.012 & 0.013 & 0.0017 & 9.0 & $<\mathrm{LOD}$ & NA & NA \\
\hline S14 & 0.0049 & $<\mathrm{LOD}$ & NA & NA & $<\mathrm{LOD}$ & NA & NA \\
\hline S15 & 0.0024 & $<\mathrm{LOD}$ & NA & NA & $<\mathrm{LOD}$ & NA & NA \\
\hline Plasma BL & 0 & $<\mathrm{LOD}$ & NA & NA & $<\mathrm{LOD}$ & NA & NA \\
\hline QCH & 5.82 & 7.4 & 1.2 & 28 & 3.1 & 0.029 & 47 \\
\hline QCM & 0.582 & 0.54 & 0.021 & 7.4 & 0.29 & 0.051 & 51 \\
\hline QCL & 0.0582 & 0.06 & 0.001 & 0.21 & 0.02 & 0.010 & 70 \\
\hline Sample & 88 & 88 & 2.6 & 0.23 & 93 & 4.7 & 5.7 \\
\hline Mean \pm SD & & & & $9.4 \pm 8.0$ & & & $40 \pm 20$ \\
\hline
\end{tabular}

Mean, SD, and accuracy (\%error) for standards, QCs, and a clinical anthrax sample are shown

\section{Discussion}

Here, we report development and validation of a method that quantifies LTx complex. Combining the strategy that provided sensitive LF detection with selective PA purification allowed sensitive measurements for LTx. It is more sensitive, $0.033 \mathrm{ng} /$ $\mathrm{mL}$ for $2 \mathrm{~h}$ and $0.0075 \mathrm{ng} / \mathrm{mL}$ for the 18 -h reaction, and more accurate than other methods for PA [2-9]. The two reaction times provide quantitation over a large dynamic range, from 24 to $0.0012 \mathrm{ng} / \mathrm{mL}$, which is extended even higher with sample dilutions, as seen with the highest infection sample at 12 , $100 \mathrm{ng} / \mathrm{mL}$. With a $2-\mathrm{h}$ reaction, the method achieves a relatively fast 4-h total time to detection and is still extremely sensitive compared with other methods. The longer incubation time improves the detection limit 4.7-fold and assists in confirming low-level positives, ruling out negatives and confirmation of low-level quantification.

Accuracy within the defined quantifiable ranges was high $(0.1-13 \%$ error) under all conditions in plasma, including those with other toxins expected to be present during infection. In a less optimal matrix such as serum, accuracy was acceptable ( $17 \pm 14 \%$ error) but had greater variability compared with plasma $(7.7 \pm 6.8 \%)$. This may be due to serum collection that can include varying degrees of neutrophil lysis and release of defensins which are reported to decrease LF activity [35]. Serum preparation may also initiate the clotting cascade that releases proteases that could artificially cleave and activate PA83 to PA63, artificially increasing LTx measured. This was not observed when PA83 was spiked along with LF in either serum or plasma. There was no consistency in whether LTx measured in serum was increased or decreased. When spiked in various donor samples, LTx was higher in serum than plasma. When spiked with PA63 and LF separately, LTx was lower in serum than plasma. For LTx quantification, either matrix can be used but plasma is preferred.

Three steps, antibody purification, enzymatic activity, and mass spectrometric detection of specific cleavage products, combine to minimize cross reactivity. Taken together, it provided specificity of $100 \%$. Sensitivity was also $100 \%$ with no false negatives for 3 humans and 24 rhesus macaque inhalation infections. Though the human inhalation anthrax case numbers for which samples were available was low, the sensitivity was supported by the positive results in 24 inhalationinfected rhesus macaques and was further supported by positive results following antibiotic treatment in all nine available treated subjects and as long as 8 days post-antibiotics in one case [26]. This is also important in terms of diagnostic 
Table 4 Impact of antimicrobial agents on LTx detection during inhalation anthrax in rhesus macaques treated with Ciprofloxacin (Cipro) commencing at the time point indicated 48 or $72 \mathrm{~h}$ post- challenge (PC) and in human clinical cases treated with antimicrobial agents following hospitalization

\begin{tabular}{|c|c|c|c|c|c|c|}
\hline Subject & Status & Antimicrobials & $\begin{array}{l}\text { Pre-Abx } \\
\text { LTx (ng/mL) }\end{array}$ & $\begin{array}{l}\text { Sample time } \\
\text { pre-Abx }\end{array}$ & $\begin{array}{l}\text { Last post-Abx } \\
\text { LTx (ng/mL) }\end{array}$ & $\begin{array}{l}\text { Sample time } \\
\text { post-Abx }\end{array}$ \\
\hline RM (R050003) & NS (72 h) & Cipro 48 h PC & 14 & $36 \mathrm{~h} \mathrm{PC}$ & 8.6 & 36 h (LA) \\
\hline RM (04208) & NS (6 days) & Cipro 48 h PC & 280 & $48 \mathrm{~h} \mathrm{PC}$ & 8.7 & $72 \mathrm{~h}(\mathrm{LA})$ \\
\hline RM (03E062 & $\mathrm{S}$ & Cipro 48 h PC & 7.6 & $48 \mathrm{~h} \mathrm{PC}$ & 0.095 & $48 \mathrm{~h}$ \\
\hline RM (04E067) & $\mathrm{S}$ & Cipro 48 h PC & 12 & $48 \mathrm{~h} \mathrm{PC}$ & 0.096 & $72 \mathrm{~h}$ \\
\hline RM (0412) & $\mathrm{S}$ & Cipro 72 h PC & 8.3 & $72 \mathrm{~h} \mathrm{PC}$ & 0.072 & $72 \mathrm{~h}$ \\
\hline RM (04E083) & $\mathrm{S}$ & Cipro 72 h PC & 2.3 & $72 \mathrm{~h} \mathrm{PC}$ & 0.12 & $72 \mathrm{~h}$ \\
\hline Human (2006) & $\mathrm{S}$ & At admission & 2.6 & $3 \mathrm{DPO}$ & 0.012 & 8 days \\
\hline Human (2008) & NS & At admission & NA & NA & 0.018 & 6 days (FA) \\
\hline Human (2011) & S & At admission & 2.3 & $2 \mathrm{DPO}$ & 0.023 & $68 \mathrm{~h}$ \\
\hline
\end{tabular}

The LTx results are given for samples obtained prior to antimicrocrobial treatment (Pre-Abx) and the last available sample positive (post-Abx) $N A$ not available, $N S$ non-survival, $S$ survived, $L A$ latest available post-antibiotic sample, $F A$ first available, $A b x$ antimicrobials/antibiotics, $D P O$ days post-symptom onset

potential, since antibiotic use renders methods that depend on the organism such as culture and PCR, negative, usually within $24 \mathrm{~h}$ following treatment initiation.

This method may be useful for evaluation of the efficacy of PA-targeted therapeutics such as AIGIV. There was higher error of $40 \pm 20 \%$ from AIG at LTx levels below $1 \mathrm{ng} / \mathrm{mL}$, which was similar to that seen previously for a TRF PA assay with a $50 \%$ reduction in signal for a 5.4-fold ratio of AIG to PA [5]. However, LTx was still detectable at low levels, $0.024 \mathrm{ng} / \mathrm{mL}$, even with extreme excesses of $200 \mu \mathrm{g} / \mathrm{mL}$ anti-PA IgG. Thus, any negative impact on detection was small in context of the detection limit. There was no interference in an AIG-spiked clinical sample. Though it reduces the ability to accurately measure LTx at lower levels, in vitro, it is expected that during treatment, AIG binding PA63 would actually reduce circulating levels in vivo. The in vitro interference could be a measure of in vivo LTx clearance. The utility of this method for AIG will be validated further.

Previous reports of freely circulating LTx complex in terminal samples in rabbits, guinea pigs, and monkeys [18, 20, $36]$, were confirmed in this study in rhesus macaques. The sensitivity of this method allowed the first detection of catalytically active LTx early and throughout infection. That LTx increases to high levels in late infection, suggests its importance in the process of infection and rapid death. In all, these results demonstrated the importance of LTx as a diagnostic

Table 5 Comparison of LTx quantification with other anthrax diagnostic biomarkers, bacteremia (bact), pagA PCR, and total LF, over the course of inhalation anthrax in two rhesus macaques

\begin{tabular}{|c|c|c|c|c|c|c|}
\hline \multirow[t]{2}{*}{ Time PC } & \multicolumn{3}{|l|}{$16 \mathrm{~N}$} & \multicolumn{3}{|l|}{$89 \mathrm{~N}$} \\
\hline & Bact/PCR & LTx & Total LF & Bact/PCR & LTx & Total LF \\
\hline-30 days & - & $<\mathrm{LOD}$ & $<\mathrm{LOD}$ & - & $<\mathrm{LOD}$ & $<\mathrm{LOD}$ \\
\hline $12 \mathrm{~h}$ & - & NT & $<\mathrm{LOD}$ & - & NT & $<\mathrm{LOD}$ \\
\hline $18 \mathrm{~h}$ & - & NT & 0.026 & - & NT & $<\mathrm{LOD}$ \\
\hline $24 \mathrm{~h}$ & - & $<\mathrm{LOD}$ & $0.13 \pm 0.016$ & - & NT & $0.049 \pm 0.012$ \\
\hline $30 \mathrm{~h}$ & - & $<\mathrm{LOD}$ & $0.69 \pm 0.044$ & - & $<\mathrm{LOD}$ & $0.32 \pm 0.061$ \\
\hline $36 \mathrm{~h}$ & $\pm /+$ & $0.24 \pm 0.041$ & $1.8 \pm 0.16$ & $+/+$ & $0.10 \pm 0.012$ & $2.2 \pm 0.51$ \\
\hline $48 \mathrm{~h}$ & $+/+$ & $0.76 \pm 0.074$ & $13 \pm 1.0$ & $+/+$ & $1.02 \pm 0.039$ & $30 \pm 1.5$ \\
\hline $72 \mathrm{~h}$ & $+/+$ & $21 \pm 0.54$ & $53 \pm 3.7$ & $+/+$ & $1.25 \pm 0.079$ & $20 \pm 0.64$ \\
\hline $96 \mathrm{~h}$ & NA & $5.4 \pm 1.4$ & $22 \pm 0.35$ & NA & $12 \pm 1.5$ & $72 \pm 2.7$ \\
\hline $120 \mathrm{~h}$ & $+/+$ & $12,100 \pm 1270$ & $12,200 \pm 670$ & $+/+$ & $1150 \pm 170$ & $1930 \pm 44$ \\
\hline
\end{tabular}

Bact is positive ( + ) for $\geq 6$ colonies in the primary streak, low positive $( \pm$ ) for one to five colonies, negative $(-)$ for no colonies. Qualitative pagA PCR is positive $(+)$ or negative $(-)$. LOD $=0.0075 \mathrm{ng} / \mathrm{mL}$ for LTx and $0.005 \mathrm{ng} / \mathrm{mL}$ for total LF. All samples with available volumes were analyzed in duplicate at minimum and at one or more dilutions

$P C$ post-challenge, $N A$ not analyzed 
and therapeutic target. The method described should provide a sensitive, fast, accurate tool for anthrax toxin detection and evaluation of PA-directed therapeutics.

Disclaimer The findings and conclusions in this report are those of the authors and do not necessarily represent the views of the Centers for Disease Control and Prevention

Open Access This article is distributed under the terms of the Creative Commons Attribution License which permits any use, distribution, and reproduction in any medium, provided the original author(s) and the source are credited.

\section{References}

1. Young JA, Collier RJ (2007) Anthrax toxin: receptor binding, internalization, pore formation, and translocation. Annu Rev Biochem 76: 243-265

2. Mabry R, Brasky K, Geiger R, Carrion R Jr, Hubbard GB, Leppla S, Patterson JL, Georgiou G, Iverson BL (2006) Detection of anthrax toxin in the serum of animals infected with Bacillus anthracis by using engineered immunoassays. Clin Vaccine Immunol 13(6):671677

3. Tang S, Moayeri M, Chen Z, Harma H, Zhao J, Hu H, Purcell RH, Leppla SH, Hewlett IK (2009) Detection of anthrax toxin by an ultrasensitive immunoassay using europium nanoparticles. Clin Vaccine Immunol 16(3):408-413

4. Cohen N, Mechaly A, Mazor O, Fisher M, Zahavy E (2014) Rapid homogenous time-resolved fluorescence (HTRF) immunoassay for anthrax detection. J Fluoresc 24(3):795-801

5. Stoddard RA, Quinn CP, Schiffer JM, Boyer AE, Goldstein J, Bagarozzi DA, Soroka SD, Dauphin LA, Hoffmaster AR (2014) Detection of anthrax protective antigen (PA) using europium labeled anti-PA monoclonal antibody and time-resolved fluorescence. J Immunol Methods 408:78-88

6. Farrow B, Hong SA, Romero EC, Lai B, Coppock MB, Deyle KM, Finch AS, Stratis-Cullum DN, Agnew HD, Yang S, Heath JR (2013) A chemically synthesized capture agent enables the selective, sensitive, and robust electrochemical detection of anthrax protective antigen. ACS Nano 7(10):9452-9460

7. Dragan AI, Albrecht MT, Pavlovic R, Keane-Myers AM, Geddes CD (2012) Ultra-fast $\mathrm{pg} / \mathrm{ml}$ anthrax toxin (protective antigen) detection assay based on microwave-accelerated metal-enhanced fluorescence. Anal Biochem 425(1):54-61

8. Mechaly A, Cohen N, Weiss S, Zahavy E (2013) A novel homogeneous immunoassay for anthrax detection based on the AlphaLISA method: detection of $\mathrm{B}$. anthracis spores and protective antigen (PA) in complex samples. Anal Bioanal Chem 405(12):3965-3972

9. Ghosh N, Gupta N, Gupta G, Boopathi M, Pal V, Goel AK (2013) Detection of protective antigen, an anthrax specific toxin in human serum by using surface plasmon resonance. Diagn Microbiol Infect Dis 77(1):14-19

10. Liu S, Crown D, Miller-Randolph S, Moayeri M, Wang H, Hu H, Morley T, Leppla SH (2009) Capillary morphogenesis protein-2 is the major receptor mediating lethality of anthrax toxin in vivo. Proc Natl Acad Sci U S A 106(30):12424-12429

11. Liu S, Leppla SH (2003) Cell surface tumor endothelium marker 8 cytoplasmic tail-independent anthrax toxin binding, proteolytic processing, oligomer formation, and internalization. J Biol Chem 278(7): $5227-5234$
12. Petosa C, Collier RJ, Klimpel KR, Leppla SH, Liddington RC (1997) Crystal structure of the anthrax toxin protective antigen. Nature 385(6619):833-838

13. Kintzer AF, Thoren KL, Sterling HJ, Dong KC, Feld GK, Tang II, Zhang TT, Williams ER, Berger JM, Krantz BA (2009) The protective antigen component of anthrax toxin forms functional octameric complexes. J Mol Biol 392(3):614-629

14. Mogridge J, Cunningham K, Collier RJ (2002) Stoichiometry of anthrax toxin complexes. Biochemistry 41(3):1079-1082

15. Abrami L, Liu S, Cosson P, Leppla SH, van der Goot FG (2003) Anthrax toxin triggers endocytosis of its receptor via a lipid raftmediated clathrin-dependent process. J Cell Biol 160(3):321-328

16. Leppla SH (1982) Anthrax toxin edema factor: a bacterial adenylate cyclase that increases cyclic AMP concentrations of eukaryotic cells. Proc Natl Acad Sci U S A 79(10):3162-3166

17. Duesbery NS, Webb CP, Leppla SH, Gordon VM, Klimpel KR, Copeland TD, Ahn NG, Oskarsson MK, Fukasawa K, Paull KD, Vande Woude GF (1998) Proteolytic inactivation of MAP-kinasekinase by anthrax lethal factor. Science 280(5364):734-737

18. Ezzell JW Jr, Abshire TG (1992) Serum protease cleavage of Bacillus anthracis protective antigen. J Gen Microbiol 138(3):543-549

19. Moayeri M, Wiggins JF, Leppla SH (2007) Anthrax protective antigen cleavage and clearance from the blood of mice and rats. Infect Immun 75(11):5175-5184

20. Panchal RG, Halverson KM, Ribot W, Lane D, Kenny T, Abshire TG, Ezzell JW, Hoover TA, Powell B, Little S, Kasianowicz JJ, Bavari S (2005) Purified Bacillus anthracis lethal toxin complex formed in vitro and during infection exhibits functional and biological activity. J Biol Chem 280(11):10834-10839

21. Boyer AE, Quinn CP, Woolfitt AR, Pirkle JL, McWilliams LG, Stamey KL, Bagarozzi DA, Hart JC Jr, Barr JR (2007) Detection and quantification of anthrax lethal factor in serum by mass spectrometry. Anal Chem 79(22):8463-8470

22. Boyer AE, Gallegos-Candela M, Lins RC, Kuklenyik Z, Woolfitt A, Moura H, Kalb S, Quinn CP, Barr JR (2011) Quantitative mass spectrometry for bacterial protein toxins - a sensitive, specific, highthroughput tool for detection and diagnosis. Molecules 16(3):23912413

23. Kuklenyik Z, Boyer AE, Lins R, Quinn CP, Gallegos-Candela M, Woolfitt A, Pirkle JL, Barr JR (2011) Comparison of MALDI-TOFMS and HPLC-ESI-MS/MS for endopeptidase activity-based quantification of anthrax lethal factor in serum. Anal Chem 83:1760-1765

24. Gallegos-Candela M, Boyer AE, Quinn CP, Woolfitt AR, Barr JR (2009) Validation of rapid, sensitive, quantitative MALDI-TOF MS assays for anthrax lethal factor and lethal toxin. In: Bacillus-ACT 2009: The International Bacillus anthracis, B. cereus, and B. thuringiensis conference, Santa Fe, NM

25. Boyer AE, Quinn CP, Hoffmaster AR, Kozel TR, Saile E, Marston CK, Percival A, Plikaytis BD, Woolfitt AR, Gallegos M, Sabourin P, McWilliams LG, Pirkle JL, Barr JR (2009) Kinetics of lethal factor and poly-D-glutamic acid antigenemia during inhalation anthrax in rhesus macaques. Infect Immun 77(8):3432-3441

26. Walsh JJ, Pesik N, Quinn CP, Urdaneta V, Dykewicz CA, Boyer AE, Guarner J, Wilkins P, Norville KJ, Barr JR, Zaki SR, Patel JB, Reagan SP, Pirkle JL, Treadwell TA, Messonnier NR, Rotz LD, Meyer RF, Stephens DS (2007) A case of naturally acquired inhalation anthrax: clinical care and analyses of anti-protective antigen immunoglobulin G and lethal factor. Clin Infect Dis 44(7):968-971

27. Sprenkle MD, Griffith J, Marinelli W, Boyer AE, Quinn CP, Pesik NT, Hoffmaster A, Keenan J, Juni BA, Blaney DD (2014) Lethal factor and anti-protective antigen IgG levels associated with inhalation anthrax, Minnesota, USA. Emerg Infect Dis 20(2):310-314

28. Mytle N, Hopkins RJ, Malkevich NV, Basu S, Meister GT, Sanford DC, Comer JE, Van Zandt KE, Al-Ibrahim M, Kramer WG, Howard C, Daczkowski N, Chakrabarti AC, Ionin B, Nabors GS, Skiadopoulos MH (2013) Evaluation of intravenous anthrax immune 
globulin for treatment of inhalation anthrax. Antimicrob Agents Chemother 57(11):5684-5692

29. HHS-FDA, CDER (2001) Guidance for industry: bioanalytical method validation. Rockville, MD

30. Armbruster DA, Pry T (2008) Limit of blank, limit of detection and limit of quantitation. Clin Biochem Rev Aust Assoc Clin Biochem 29(Suppl 1):S49-S52

31. Anaraki S, Addiman S, Nixon G, Krahe D, Ghosh R, Brooks T, Lloyd G, Spencer R, Walsh A, McCloskey B, Lightfoot N (2008) Investigations and control measures following a case of inhalation anthrax in East London in a drum maker and drummer, October 2008. Euro Surveill 13(51)

32. Melnyk RA, Hewitt KM, Lacy DB, Lin HC, Gessner CR, Li S, Woods VL Jr, Collier RJ (2006) Structural determinants for the binding of anthrax lethal factor to oligomeric protective antigen. J Biol Chem 281(3):1630-1635
33. Taylor JK (1987) Quality assurance of chemical measurements. CRC Press LLC, United States

34. Boyer AE, Quinn CP, Hoffmaster AR, Kozel T, Gallegos M, Saile E, Marston C, Beesley C, Percival A, Lins R, Woolfitt A, Pirkle JL, Barr JR (2010) Association of early lethal factor levels with survival during inhalation anthrax in rhesus macaques. In: ASM Biodefense and Emerging Diseases Research Meeting, Baltimore, MD. American Society for Microbiology

35. Kim C, Gajendran N, Mittrucker HW, Weiwad M, Song YH, Hurwitz R, Wilmanns M, Fischer G, Kaufmann SH (2005) Human alphadefensins neutralize anthrax lethal toxin and protect against its fatal consequences. Proc Natl Acad Sci U S A 102(13):4830-4835

36. Ezzell JW, Abshire TG, Panchal R, Chabot D, Bavari S, Leffel EK, Purcell B, Friedlander AM, Ribot WJ (2009) Association of Bacillus anthracis capsule with lethal toxin during experimental infection. Infect Immun 77(2):749-755 